\title{
KANTTEEKENINGEN OVER CULTURES IN SURINAME EN ELDERS
}

\author{
DOOR \\ TJ. PYTTERSEN
}

Er worden den laatsten tijd van verschillende zijden ${ }^{1}$ ) meeningen over Suriname verspreid, welke ò zeer aanvechtbaar òf onjuist zijn. Zij hebben mij aanleiding gegeven, mede op verzoek, tot het schrijven van dit artikel.

Onjuist is natuurlijk de meening, dat de bodem van het geheele land een hooge cultuurwaarde bezit, maar eveneens is het onjuist te beweren, dat slechts het oeverland, oude planters spraken van mangrogronden, langs de benedenrivieren voor cultuurbedrijven geschikt is. Het aangeslibde kustland bestaat uit verschillende typen klei van welke de meeste buitengewoon vruchtbaar zijn. Dat kustland wordt doorsneden door schelpen- en zandritsen of een mengsel van beide waaronder er voorkomen van zeer opmerkelijke vruchtbaarheid. In het algemeen ligt het kustland beneden hoogwaterpeil, waardoor het oeverland geregeld wordt overstroomd en het regenwater op het vlakke land, dat verder van de rivieren gelegen is, wordt opgestuwd. Achter het oeverland vindt men om die reden dan ook gewoonlijk met biezen of lichte palmbosschen - palissaden, in Indië pinah genaamd - bedekte vlakten. De afzetting van slib heeft de cultuurwaarde van dat oeverland verhoogd, waarop echter ook veelal de betere waterloozing van het eerste gedeelte der polders van invloed is. Het lage land n.l. kan zonder inpoldering niet voor cultuurbedrijven worden benut. Bij eb kan door de sluizen worden afgewaterd en kan practisch gesproken

1) O.m. J. Sibinga Mulder in ,,De Ind. Mercuur” No 40. d. d. 30 October '28.

West Indische Gids XI 
tot 8 K.M. van den oever een natuurlijke loozing worden toegepast. Velen in de kolonie en daarbuiten hebben neiging grond, welke in samenstelling niet met het beste mangroland overeenkomt, voor loonende bedrijven ongeschikt te noemen. Op die manier zou bijv. een Nederlandsche landbouwer, die zijn bedrijf op de beste Zeeuwsche klei uitoefent, de bodemwaarde van minder vruchtbaren bouwgrond in ons vaderland voor landbouw ongeschikt kunnen noemen. Dank zij het bezit van uitstekende (water)wegen kon het plantagebedrijf in het door forten beschermde kustgebied eertijds snel toenemen. Het was een verstandige politiek om slechts kleine strooken gronds langs de rivieren uit te geven, waardoor vele plantages van die stroomen voor transport en waterafvoer konden gebruik maken. Die eerste planters zagen neer op elken grond, welke verder van de rivieren gelegen was. Toen men door nood gedrongen dergelijken grond ging benutten, veranderde deze ongunstige meening spoedig en kreeg men meer inzicht in de bodemwaarde, waarbij vooral de vegetatie der terreinen een goede leiddraad was. Ik heb over dit alles meer uitvoerig geschreven in een artikel voorkomende in „De W. I. Gids" van December 1922, zoodat ik kortheidshalve daarnaar refereer. Deze met biezen en hier en daar met palissaden bedekte vlakten werden biri-biri-landen genoemd. Teenstra (1835) schrijft: „De geschikste gronden tot het aanleggen van een koffyplantaadje zijn nieuwe kleigronden, vooral op mangrove-gronden, zijnde die, op welke vele pinapalmen groeien, groeit de koffy boon tevens zeer weelderig, .... Naast de blauwe kleigronden volgen in geschiktheid de bieriebierielanden, mits dezelve niet uit leemachtige klei bestaan”. A. Blom (1805) zegt: „Biri-birigronden waar papayen en stoelbiezen groeien, dat zeer vette en vrugtbare Gronden zijn".

Het verlengen van de Orleanakreek, het graven der kanalen van Matappica, Warappa en Tapoerina, wijst er op, dat de vroegere planters vertrouwen hadden in de verder van de rivieren gelegen terreinen. In genoemd artikel van December ' 22 heb ik gewezen op de streken benoorden de 
Cottica en Commewyne en verder op het ongeveer 400.000 H.A. groote terrein tusschen de Coppename- en Nickerierivieren. De begroeiing van dit terrein, welke op het daarbij afgedrukte tracé-kaartje voorkomt, wijst op grootendeels waardevol land. Zonder het oprichten van pompstations, welke een deel van het jaar het overtollige water zullen moeten afvoeren, zal men op genoemd terrein nooit veel bereiken. Verder heb ik in dat artikel ook gewezen op de open vlakten bij Nickerie en heb ik bij mijn terugkomst uit de kolonie autoriteit en groote ondernemers op de mogelijke waarde van dit terrein voor cultuurbedrijven gewezen.

Er zij hier verder vermeld, dat hoewel er in de kolonie zeer stijve klei voorkomt, lang niet alle klei slecht doorlaatbaar is en dat die doorlaatbaarheid toeneemt naar het Westen. Hier vindt men zeer mooie met humus bedekte klei, welke overeenkomt met die in Britsch Guyana maar over het algemeen een grootere vruchtbaarheid bezit.

Naar mate men zich verder van de zee verwijdert wordt de grond in het alluviale gebied van Suriname lichter. Een bekend planter sprak indertijd een ongunstige meening uit over de bodemwaarde van de koffieplantage Slootwijk, waar reeds een ander grondtype wordt aangetroffen. Toen hij hoorde, dat men daar bezig was koffie op zandgrond te planten, liet hij zich hierover afkeurend uit. Ik meen, dat de resultaten op deze onderneming nu niet direct slecht zijn en dat ook op zand althans een groot deel van den aanplant zeer bevredigende resultaten geeft. Maar al zijn die resultaten minder dan op mangroland, wij beschikken in onzen tijd over middelen, welke op loonende wijze de productiviteit van den bodem kunnen vermeerderen.

De samenstelling van de hoogerop gelegen gronden is uiteenloopend, daar het gehalte aan zand in den bodem verschilt. In „De W.I. Gids” van Mei 1923 heb ik het oordeel van verschillende vroegere planters omtrent een deel der lichtere gronden medegedeeld en verwijs ik wederom kortheidshalve daarnaar. Maar ook reeds tevoren heb ik over de cultuurwaarde dier hooger gelegen terreinen het 
een en ander gepubliceerd uitsluitend mij beroepende op hetgeen ik daaromtrent in de oude litteratuur gevonden had. Dit alles heeft veel stof doen opwaaien. In het „Verslag over de jaren 1924/'27. Departement Landbouwproefstation in Suriname" lezen wij nu o.m. :

„Ook de cultuur van sisal, tabak en thee zal op de lichtere gronden ten Zuiden van de alluviale kuststrook met stijve klei beproefd worden. Ook voor cacao zijn de vooruitzichten op deze lichte, doorlatende, vruchtbare gronden niet slecht.... Het is dringend noodig, dat op deze lichtere gronden, die ten deele zeer vruchtbaar zijn, proeven met de bovengenoemde nieuwe cultures worden genomen".

„Voor een herleving van de cacaocultuur in Suriname bieden de alluviale streken buiten het poldergebied gelegen, uit een landbouwtechnisch oogpunt beschouwd, goede voorwaarden aan. Hier zijn het lichtere klei-, leem -en zandgronden met een bouwkruin tot een diepte van $1 \mathrm{M}$. en meer".

„Samen met den Landbouwscheikundige J. W. van Dijk werd langs de Tempati, Mapane, Boven Suriname door het slaan van proefgaten de gesteldheid van den bouwkruin nagegaan. Gebleken is dat de alluviale streken buiten het zoutwatergebied gelegen, goede bodemcondities leveren voor landbouwdoeleinden".

Ter versterking van bovenstaande meen ik goed te doen iets uit het artikel van den Heer C. van Drimmelen voorkomende in „De W. I. Gids” van Juni 1928 over te nemen. Genoemde heer heeft als Districts-commissaris het district Nickerie leeren kennen.

„Het Noordelijkste gedeelte van den rechteroever (van de Corantynrivier) bestaat uit zachte klei. Bij elken springvloed wordt het overstroomd.... Boven de Kalebaskreek, omtrent 15 K.M. van den mond, en ter hoogte van de eilanden „de Zusters” verheft de kleioever zich reeds zichtbaar boven het hoogwaterpeil. Het bosch op dit zee- rivier alluvium is een galerijbosch. Daarachter treft men een z.g. kleisavanna aan begroeid met allerlei grassoorten, biezen en hier en daar met houtgewas. Deze na- 
genoeg boomlooze vlakte strekt zich in Oostelijke richting uit naar de Nickerierivier, zet zich aan gene zijde daarvan voort en is geschikt o.m. voor de teelt van suikerriet, katoen en rijst. Duizenden hectaren vruchtbaar land liggen hier beschikbaar voor den landbouw gemakkelijk te draineeren en gunstig gelegen voor de verscheping.... Een eindweegs boven de eilanden de Zusters bestaat de oever nog altijd uit alluviale klei, doch hoogerop maakt deze plaats voor diluviale gronden, saamgesteld uit de verweringsproducten van graniet, gneis, diabaas en dioriet, gemengd soms doch ook wel door het water daarin afwisselend zand en leemlagen neergelegd".

\section{Savannas.}

Veelal hoort men spreken over de onvruchtbare savannas van Suriname. Bedoeld worden dan de zandsavannas, welke bezuiden het alluvialegebied worden aangetroffen en welke zich verder over het geheele achterland tot diep in Brazilië verspreiden. De zeer uitgestrekte, dikwijls uiterst vruchtbare biezenvlakten in het kustgebied worden echter eveneens savannas genoemd en moet men dus als over savannas wordt geschreven wel even aangeven wat wordt bedoeld. Deze klei-savannas bestaan weer uit twee soorten en is die met een leem-caolienbodem voor cultures niet van beteekenis. In het boven reeds aangehaald nummer van „De W. I. Gids” van December 1922 heb ik een foto van een dergelijke leemsavanna indertijd door den heer J. W. Gonggrijp bezocht doen opnemen. Wat nu de zandsavannas betreft dient te worden opgemerkt, dat men deze naar graden van onvruchtbaarheid in kan deelen, dat wil zeggen dat voor zoover thans is te overzien zij nimmer voor cultures van eenig belang zullen zijn. In hoeverre die geschiktheid bevorderd zal worden door goede drainage en bevloeiing kan hier buiten beschouwing worden gelaten. Reeds oude schrijvers wezen erop, dat deze beide middelen de vruchtbaarheid vermeerderden. De zooeven genoemde heer Gonggrijp, de bekwame oud-houtvester van de kolonie, heeft in een artikel in „De W. I. Gids” van Mei 1922 gewezen op de 
groote overeenkomst tusschen de voor veeteelt uiterst geschikte savannas in Venezuela en die in Suriname. Dat artikel is zeer lezenswaardig. Vaststaat, dat wij die zandsavanna niet waardeloos mogen noemen.

\section{Achterland.}

Het min of meer heuvelachtige land volgend op en in de omgeving van de zandsavannastrook, de savannazône, heeft ook al geen goeden naam. Bewezen kan echter worden, dat er niet altijd ongunstig over gesproken is geworden. Hier komen o.m. typische steengronden voor waarop meerdere cassaveoogsten achtereen worden verkregen, hetgeen wijst op vruchtbaren grond. Diabaasverweringsproducten schijnen hier te worden aangetroffen. Een met groote energie indertijd door den heer Junker opgemakkt rapport over het terrein tusschen de Suriname- en Commewijnerivier, thans berustend op het Ministerie van Koloniën, bevat enkele interessante gegevens over die streek, welke ten deele in „De W. I. Gids” zijn vermeld geworden. Het boven reeds vermeldde „Verslag over 1924/ '27' zegt over de gronden in deze zône:

„Zal de cacaocultuur hier ooit weer herleven, dan moeten daarvoor - ziet men van den zeer kostbaren aanleg van irrigatie-werken in ons polderland af - de lichtere, vruchtbare, diepe gronden in de Savanen-zône worden gekozen".

Op blz. 16/17 wordt geschreven dat twee bij name genoemde planters: „onze lichte vruchtbare gronden in de Savanenzône in ons altijd zonnig klimaat en de niet zeer scherpe droge tijden bij uitstek geschikt achten voor de cultuur van den oliepalm".

Op blz. 7 van genoemd verslag lezen wij nog:

„De binnenlanden ten Zuiden van den vijfden breedte graad bleken weinig vruchtbaar te wezen. Langs de grootere rivieren is het land, dat jaarlijks gedurende den zwaren regentijd wordt overstroomd, iets vruchtbaarder, doch ook daar zal nauwelijks een welvarend landbouwbedrijf zich kunnen vestigen".

Dat ziet er leelijk uit en gelijkt sterk op uitspraken, welke we eenige jaren terug over de zooevengenoemde 
lichtere gronden hoorden. Dit ongunstige oordeel is grootendeels gebaseerd op een uitspraak van wijlen Prof. Harrison uit Britsch Guyana en is niet overeenstemmend met dat hetwelk wij in de bekende „Handbooks” aantreffen.

Tegelijk met het bespreken van de cultuurwaarde van het achterland, wensch ik de aandacht te vestigen op een andere voor Suriname ongunstige uitspraak n.l. deze, dat het rivierwater geen vruchtbaar slib meevoert om reden de gesteenten in het hoogland voor den landbouw van geen waarde zijn daar de verweringsproducten practisch geen voedingsstoffen bevatten. Zelfs velen der meest verstokten in deze moeten nog erkennen, dat langs de bovenrivieren dikwijls zeer waardevolle slibafzettingen worden aangetroffen en kunnen niet ontkennen, dat aan de vorming van zwaar hoog bosch in het binnenland slibafzettingen door overstrooming in den grooten regentijd debet zijn.

Vroegere planters, die hun bedrijven uitoefenden op de hoogere, lichtere gronden, hebben opgemerkt, dat na overstrooming hunner velden de bodemproductiviteit belangrijk toenam. Komt men er later ooit toe in het binnenland cultuurbedrijven op te zetten dan zijn waterbouwkundige werken daarvoor noodig en hieronder ook bevloeiingswerken; immers de practijk heeft reeds geleerd dat de rivieren in den regentijd vruchtbaar slib meevoeren. De mogelijkheid de terreinen in het binnenland met slibhoudend water te kunnen bevloeien is van groote waarde voor cultuurbedrijven.

Ik wil niet ontkennen, dat er vele gesteenten in het bergland voorkomen, welke voor den landbouw vrijwel waardeloos verweringsmateriaal leveren, maar er zijn er toch ook o.m. diabaas en graniet die dit wel doen. Waar nu het binnenland nog zoo weinig onderzocht is, kan later blijken dat de hoeveelheid van een dergelijk gunstig gesteente meevalt. Leest men oude en nieuwe expeditieverslagen dan valt op, dat belangrijke uitgestrektheden maripapalmbosschen in het binnenland voorkomen, dat elders pinapalmbosschen worden aangetroffen en ook de boegroemakapalm hier en daar in niet onbelangrijke hoeveelheden groeit. Het voorkomen dezer palmen wijst toch 
op min of meer waardevolle zwaren en lichten grond.

Er is echter meer.

Die reeds meermalen genoemde oude planters waren goede opmerkers en zeiden: ,waar goed bouwhout wordt aangetroffen, is de grond goed voor suiker". Elders leest men, dat waar de bolletrie groeit de grond goed is voor suikerriet.

$\mathrm{Nu}$ wil ik niet ontkennen, dat er terreinen voorkomen waarop de bolletrie groeit die toch niet geschikt zijn voor cultures, maar in het algemeen gesproken wijst het voorkomen van hoog mooi bosch met goed timmerhout op goeden cultuurgrond.

Hooge bosschen komen in het binnenland veelvuldig voor en de eeuwen lange ontleding van bladeren en bladresten kan de grondwaarde doen stijgen.

Steeds heb ik er in mijne artikelen op gewezen, dat wij in onzen tijd op allerlei gebied zooveel sterker dan vroeger staan om de productiviteit van den bodem op loonende wijze te verhoogen ${ }^{1}$ ).

\section{Conclusie.}

Het kustgebied van Suriname bevat tienduizenden hectaren land van een vruchtbaarheid als wij in OostIndië zelden aantreffen. De kosten voor het cultuurgeschiktmaken dezer terreinen kunnen gemiddeld (biezenland en bosch) per H.A. geschat worden op f 250-, een jaarlijksche rente vertegenwoordigende van circa f 15.- . Ik heb hier het inpolderen van groote terreincomplexen op 't oog. Het voorkomen van waterwegen maakt hier in 't algemeen den aanleg van spoorwegen overbodig.

Het zeer uitgestrekte binnenland zal voor een zeker deel een behoorlijke cultuurwaarde blijken te bezitten, indien hier wegen worden ingeslagen, die in Oost-Indië tot zeer gunstige resultaten hebben geleid.

Suriname en de Centraal-Amerikaansche landen.

Er wordt gezegd, dat de arbeidskosten per H.A. en de

1) Zie in dit verband het artikel van Dr. J. E. van Amstel: „Algemeen overzicht van ligging en bodem van Suriname" in West-Indië"' no. 2 Mei. 1921. 
bodemproductiviteit van eenige Centraal Am. landen als Costa Rica en Guatamala resp. zooveel lager en zooveel hooger zijn dan die in Suriname en speciaal worden dan cultures van bananen en cacao genoemd.

Cost a Rica.

Costa Rica behoort tot die staten welke feitelijk geheel onder den machtigen invloed staan van het Amerikaansch kapitaal w.o. de United Fruit Company.

Dr. W. Bitter schrijft in zijn boek: ,Die Eroberung Mittelamerikas durch den Bananen Trust” (1921): „Minor C. Keith (Directeur van de U. F. C.) ist die eigentliche Regent in Costa Rica". O'Henry heeft den toestand beschreven in zijn bekend werk "Cabbages and Kings". Vermeld wordt verder, dat de groote vruchtenmaatschappij in 1921 ruim 230.000 akkers in eigendom en meer dan 6600 akkers in pacht had. De inkomsten van den staat bestaan voor een deel in gelden welke uit het uitvoerrecht op bananen worden verkregen. De Fransche Consul aldaar schreef hieromtrent: „U. F. C. jouit au Costa Rica (loi du 30 Juin 1909) d'un véritable monopole d'exportation contre paiement à l'Etat; jusqu'en 1930, d'un taxe d'un cent (2\% c. Holl.) par régime".

Volgens W. H. Koebel in diens boek "Central America” bedraagt het aantal inwoners ong. 400.000 en is integenstelling met vele der buurtlanden de bevolking bijna zuiver blank. $\mathrm{Zij}$ is wederom in tegenstelling met haar buren vrij werkzaam, om welke reden zij gaarne door de Am. maatschappijen in dienst wordt genomen. Deze maatschappijen kunnen door hun machtspositie gemakkelijk den loonstandaard enz. regelen. Minder gewenschte elementen onder de werkkrachten vinden moeilijk emplooi daar zij noch bij de maatschappijen noch bij de met deze gelieerde pachters en leveranciers werk kunnen verkrijgen. Het kan natuurlijk niet worden ontkend, dat het Am. kapitaal gesteund door de vloot rust, orde en behoorlijk betaald werk in het land heeft gebracht, maar aan den anderen kant benut het zijn positie dusdanig, dat grovere winsten dan anders worden behaald. 
Naast inheemsche werklieden vinden, evenals overal in die landen waar de U. F. C. werkt, vele West-Indiërs daar arbeid en onder deze treden vooral die van Jamaica op den voorgrond. Adams zegt in zijn „Conquest of the Tropics": „The Jamaican negro is the workman who has made possible the wonders which the U.F.C. has achieved in Central America". Dit slaat minder op Costa Rica dan op buurtlanden.

De loonstandaard in C. R. bedraagt volgens sommigen één dollar, volgens anderen (opgave Fransche Consul) $\$ 1,20-\$ 1,50$ voor een werkdag van acht uur.

Naast zeer vruchtbaar laagland, wordt in dezen staat in hoofdzaak hoogland aangetroffen. Die lage landen, voorzoover zij langs de rivieren gelegen zijn, worden jaarlijks door overstrooming met een vruchtbaar slib overdekt en kunnen daardoor langen tijd achtereen voor de cultuur van bananen worden benut tot ook hier de Panamaziekte te verwoestend optreedt.

De U. F. C. heeft volgens Prof. Stahel (Verslag van een dienstreis naar Centraal-Amerika 1923). 30.000 akkers met bananen in $\mathrm{C}$. R. beplant en koopt verder de bossen op van ongeveer 50.000 akkers land, dat door particulieren wordt bebouwd. Naar de vruchtbaarheid onderscheidt men drie soorten van bananenland. De Fransche Consul schrijft omtrent het vruchtbaarste land: „Dans la région fertile de la Estrella et de Tolamauca, les plantations donnent de 50 à 60 et même jusqu'à 70 régimes par mois en par hectare. En pleine production, une plantation de 1150 hectares donne à son propriétaire un bénéfice annuel de 36.000 dollars"'. (By 60 bossen komt dit dus uit op iets meer dan 43 dollarcent per bos). Op het hier bedoelde prima land kunnen volgens Stahel de aanplantingen het 25 tot 30 jaren uithouden alvorens de Panamaziekte tot abandonneeren der terreinen noodzaakt. Genoemde Consul noemt echter een veel korteren tijdsduur. Voor land van tweede kwaliteit is deze termijn volgens Stahel 15 jaar, voor dat van derde $5-6$ jaren. In genoemd verslag lezen we over het abandonneeren van terreinen o.m. het volgende. 
„Het land dat we hier in Good Hope in cultuur zien nemen is maar derde klas land. Het goede land in eigendom van de maatschappij is reeds vrijwel uitgeput. Tientallen van kilometers zijn we gedurende ons bezoek in Costa Rica door oud, wegens de Panamaziekte verlaten bananenland gereden, dat nu meestal met wilde kapoewerie is begroeid".

Zijn de opbrengsten op het beste land zeer hoog, de gemiddelden over groote oppervlakten zijn minder. Het verslag zegt daaromtrent: „De bijna 18000 akkers van het district Zent hebben het jaar tevoren een gemiddelde productie van 134 volle bossen per akker (335 bossen per H.A.) geleverd".

Voorts zij opgemerkt, dat de bananen van het bovenland veel fijner van smaak zijn dan die van meer laag gelegen streken. Een ongunstige factor van het land is, dat de regenval er meer dan 4000 mM. per jaar bedraagt (ongeveer twee maal meer dan in Suriname waar de over het jaar over het algemeen goed verdeelde regens en de vele zon-uren de gewassen zeer ten goede komen). Wat de aanlegkosten eener bananenplantage betreft (hierbij dient opgemerkt dat een akker in Costa Rica 0,4 HA., in Suriname 0,43 H.A. bedraagt) lezen wij: „De kosten voor den aanleg van 1 akker met bananen zijn ongeveer $\$ 25$; daarbij komen nog drainagekosten, die in het ongunstigste geval tot $\$ 20$ kunnen bedragen. De kosten voor 1 akker tot den eersten oogst zijn 40-70 dollar of 100-175 gulden". In deze kosten zijn zeker niet begrepen die voor aanschaffing van railbaanmateriaal en den aanleg der banen. „Het onderhoud, lezen wij verder, van een krachtig groeiend bananenveld is hier buitengewoon goedkoop". Ik vermoed, dat die kosten daar zeer uiteenloopend zijn, daar deze velden voorkomen op door diepe goten doorsneden terreinen, welke, indien zij langs rivieren zijn gelegen, eenigen tijd per jaar worden overstroomd terwijl die goten tevens wijzen op stijve klei. Een jaarlijksche regenval van meer dan $4000 \mathrm{mM}$. en een tropisch zonnetje zullen in de minder forsch staande aanplantingen veel opslag doen ontstaan welker bestrijding niet goedkoop is. 
Door haar bijzondere sterke positie, door de beschikking over de werkkracht van een werkwillige bevolking, door het bezitten van zeer uitgestrekte landstreken, verkeert de U. F. C. in Costa Rica in bijzonder gunstige omstandigheden. Zij kan daar, wegens het niet voorkomen van concurreerende maatschappijen groote kwanta bananen laten produceeren door kleine planters, die het risico der cultuur dragen en kan een prijs bepalen als haar goeddunkt. Genoemde Consul noemt (1922) een inkoopsprijs per vol bos van 60 dollarcent en schrijft verder: „En suite d'une campagne de presse organise par un groupe de producteurs et craignant de tuer une de ses poules aux oeufs d'or, la U. F. C. a augmenté dernièrement les prix au Costa Rica de dix cents par régime". De planters meenen recht te hebben op een dollar per bos te meer waar hun bananen van fijnere kwaliteit zijn dan die o.m. van Jamaica, waar ten gevolge der concurrentie volgens dien Consul tot twee dollar en meer per bos werd betaald. „The West Indian Committee Circular” van Juni 1923 deelt mede, dat door de concurrentie prijzen van 5 shilling 3 d. ,per payable count bunch" op Jamaica werden betaald. In Guatamala, Honduras, Nicaragua e.a. landen in die streken is de positie der U. F. C. minder krachtig en ontmoet zij een bevolking die minder werkwillig is. Voor Honduras slaagde zij er indertijd in werkkrachten uit BritschHonduras te doen aanvoeren die één dollar en meer per dag verdienden, terwijl tevens voor kost en onderdak moest worden gezorgd. In Nicaragua, de republiek van „Brown Brothers"genaamd; is de toestand thans nog niet gunstig. Er is heel wat litteratuur gedurende de laatste jaren over deze landen verschenen en al komen daar ongetwijfeld zeer gunstige natuurlijke cultuurwaarden voor, er zijn naast ongunstige binnenlandsche toestanden ook nog andere als aardbevingen en sprinkhanenplagen, orkanen, welke een ongunstigen invloed op de bedrijven hebben. Ik wil alleen nog opmerken, dat bijv. omstreeks 1915 in Honduras de waarde van woesten grond $£ 2$, van cultuur grond $£ 20$ per akker bedroeg. Dit groote verschil ( $f 60$. - tegen $f 600$. - per H.A.) wijst er wel op, 
dat het cultuurgeschikt maken van woesten grond in Centraal-Amerika in tegenstelling met Suriname ( $f$ 200$f 500$ p. H. A.) zeer kostbaar is.

Surin a m e.

Wat Suriname betreft diene er in de eerste plaats op te worden gewezen, dat de Studie Commissie van het Suriname Studie Syndicaat in haar bekend rapport o.m. schrijft: „Te oordeelen naar den stand van bacoven (bananen) en andere Musavarieteiten moet de vruchtbare kleibodem van Suriname er wel bijzonder geschikt voor zijn'. Hierbij dient niet uit 't oog te worden verloren, dat we in het algemeen omtrent de bodemwaarde van Suriname nog lang niet voldoende weten, daar er verschillende uitgestrekte streken zijn, welke tot heden nimmer ernstig in cultuur zijn genomen. Volgens de planters in de kolonie is de gemiddelde productie per H.A., in Suriname heel wat grooter dan door de Studie Commissie in haar begrooting werd aangenomen. Deze toch werd geschat op 250 volle bossen per H.A. voor het 2 de jaar, voor het 3 de 500 , vierde 500 , vijfde 500 . De langs veiligen weg verkregen kostprijs per bos bedroeg volgens die begrooting één gulden of 40 dollarcent. Hierin zijn dan niet begrepen tantièmes, kapitaalrente en afschrijving. De planters nemen verder aan dat de gronden 10 tot 20 jaar in cultuur kunnen blijven. Het is zeker niet onmogelijk, dat in de kolonie grootere complexen grond gevonden worden dan die van Accaribo, waar bijv. de koffie bijna twee maal meer opbrengt dan op de andere Surinaamsche plantages.

C a c a o.

Wat de cacaocultuur betreft diene het volgende.

Prof. Stahel schrijft in het verslag van zijn dienstreis, dat de cacao in Costa Rica het best produceert op tweede rangs bananenland, stijvere kleiachtige gronden dus. Er komen daar terreinen voor, waarvan 400-450 Kgr. per akker geoogst worden. Van de 10.000 akkers vruchtdragende boomen echter worden per jaar ongeveer $2-2 \frac{1}{2}$ millioen Kgr. cacao geoogst. 
De cacaocultuur in Suriname wordt door verschillende ziekten en plagen bezocht, die haar bestaan hoogst twijfelachtig maken. Wanneer we deze niet hadden, zou zeer zeker de productie van Costa Rica zoo niet overtroffen dan toch bereikt worden.

Desondanks heeft de cacaocultuur het in Suriname lang volgehouden en het valt te betwijfelen of onder die omstandigheden dit ook in Costa Rica het geval zou zijn. Men zal echter zeggen dat in dit laatste land geen ziekten noch plagen in de cacao voorkomen, dat dus dergelijke vergelijkingen geen nut hebben. Daarop kan ik het volgende antwoorden.

Wij lezen in genoemd verslag: ,'s Middags bezoeken we de Indiana farm, een uitgestrekte verlaten bananenplantage, die nu voor een groot deel in cacao is omgezet. Hier zien we verscheidene gevallen van de wortelziekte; dikwijls 4-6 boomen bij elkander. Zal deze ziekte, die nog niet lang geleden voor het eerst in de aanplantingen werd waargenomen, zich niet verder uitbreiden, dan moeten ernstige bestrijdingsmaatregelen worden genomen. Dit heeft de heer Kress ook ten volle ingezien. „De grond bestaat hier uit een zeer vruchtbare vulkanische aarde. Het maakt daarom een vreemden indruk, wanneer we hier 500 akkers in jonge cacao zien kwijnen.... De tweejarige boompjes waren zeer zwak en leken heel sterk op uitgeputte thripsboompjes; .... Vlak bij deze velden vonden we een $7-8$ jarigen aanplant, die eveneens zeer zwak stond. De heer S. vertelde, dat deze boomen twee jaren geleden zeer goed begonnen te dragen, maar toen opeens al hun bladeren verloren hadden. „Sindsdien sukkelden ze en gaven een zeer slechte opbrengst".

Prof. Stahel toonde hier thrips aan.

Ik zal over enkele andere daar reeds voorkomende minder ernstige ziekten of plagen niet uitwijden, maar wil alleen nog het volgende naar voren brengen. Op blz. 38 lezen we:

„De berichten uit Ecuador over de buitengewoon zware verliezen, die daar ten gevolge van het plotseling optreden der krullotenziekte worden geleden, maken den heer $\mathrm{K}$. 
nogal bezorgd voor zijne zich snel uitbreidende cacaoaanplantingen en terecht; in het zeer vochtig klimaat van Costa Rica zou de krullotenziekte niet minder verwoestend optreden dan in Ecuador".

Het blijkt geenszins dat ten gevolge eener hooge bodemproductiviteit in Costa Rica met de cacaocultuur aldaar betere resultaten worden verkregen dan in Suriname.

K o s t e n.

Dat zoowel een bananen- als een cacaocultuur zooveel meer uitgaven voor veldarbeid in Suriname noodig maken, dat daardoor de rentabiliteit van die bedrijven in gen. kolonie belangrijk minder is, is eveneens zeer aanvechtbaar. We lezen dat voor onderhoud en oogsten van een $\mathrm{krac}$ htiggroeiend bananenveld in $\mathrm{C}$. R. één man noodig is voor 20-25 akkers. Dat wil dus zeggen, dat op de superieure vulkanische gronden deze ongetwijfeld gunstige resultaten worden verkregen.

Toen de Panamaziekte op dergelijke en andere terreinen begon op te treden (1909) werden uitgebreide en kostbare proeven met een diepe grondbewerking genomen. Waar practisch geen resultaten werden verkregen, is men met een dergelijke bewerking opgehouden zoodat het onderhoud niets meer beteekent. Op die manier kunnen de kosten voor onderhoud gering zijn, maar vermindert de productiviteit van den bodem. Hoe dichter een aanplant is des te minder last heeft men van wied, maar de aanplantingen op de tweede en derde klas terreinen, welke minder gesloten zijn, zullen ook wel wat meer werkkrachten voor onderhoud vorderen. Dat de U. F. C. er meer en meer toe is overgegaan van de vrije planters bananen op te koopen tegen 70 d.c. (aan boord geleverd 80 d.c.) per bos, waardoor het cultuurrisico practisch geheel op die planters rust, is een bewijs, dat de productieprijs in eigen aanplant niet belangrijk minder zal bedragen. Volgens de door de Studie Commissie voorzichtig gestelde begrooting komt in Suriname de kostprijs per zelfde bos op 40 d.c. (Zonder tantièmes, kapitaalrente en afschrijving).

De cacaoaanplantingen der U. F. C. in C. R. worden 
door gemiddeld 1 man op de 10 akkers onderhouden, tegen in Suriname 1 man op de 3 akkers. Men mag veilig aannemen, dat de C. R. arbeiders wat meer werk verzet dan de Javaan in Suriname. De eerste wordt betaald met $\$ 1-\$ 1,50$ per werkdag. Nemen we het door den Franschen Consul genoemde loon van $\$ 1,20$ aan dan komt zulks per akker op $30 \mathrm{H}$. centen, terwijl dit in Suriname komt op $33 \mathrm{H}$. c. Nemen we verder in aanmerking, dat de C. R. akker 0.4 H.A. en de Surinaamsche 0.43 H.A. groot is, dan komen we ongeveer op dezelfde kosten. In volwassen, gezonde aanplantingen hoopt de vertegenwoordiger der U. F. C. in C. R. de kostprijs per pond spoedig op 5 d.c. te zullen kunnen terugbrengen, zegt het verslag. Dit komt neer op ong. $27 \frac{1}{2}$ H.c. per K.G. In Suriname rekent men als kostprijs voor $1 \mathrm{~K}$.G. cacao gewonnen in zeer ongezonde aanplantingen 45 H.c., bij goede oogsten minder. In Juni '22 schreef Prof. Stahel mij, dat in de beste velden van pl. de Maasstroom bijv. gemiddeld 60 vruchten (800 K.G. cacao per H.A.) per boom werden verkregen, niettegenstaande deze velden zeer oud zijn. Per C. R. akker zou de productie dus 320 K.G. bedragen. De conclusie kan zijn, dat de meer-kosten in de ziektebestrijding en in de door ziekte verminderde productie zitten. Van een zeer op den voorgrond tredend gunstig verschil tengevolge van belangrijk minder veldarbeid is in C. R. vergeleken met Suriname geen sprake.

Surinaamsche koffie.

De bewering, dat het planten van Sur. koffie - een geurige Arabica - is verlaten geworden wegens een te kleine productie per eenheidsoppervlak, waardoor de cultuur niet loonend was, is onjuist. De productie bedroeg als regel één pond per boom of 500 pond per akker. Er zijn jaren te noemen, dat deze productie zeer veel hooger was. Zoo brachten in 1766 de boomen 4 pond op, terwijl in 1809 de opbrengsten wederom zeer hoog waren. Men had in Mei of Juni een kleinen vóóroogst en in Oct. of Nov. een grooteren naoogst. De rijpe bessen vielen vlug van de boomen en waren daardoor spoedig geheel waarde- 
loos. Toen men in het begin van de 19de eeuw moeilijkheden kreeg met den aanvoer van slaven en deze arbeidsmoeilijkheden geleidelijk zeer vermeerderden had men niet meer de beschikking over voldoende werkkrachten om de koffie op tijd te oogsten en is deze cultuur verlaten geworden.

\section{Liberia koffie.}

In de Liberia heeft men een koffie gevonden, welke niet alleen in Suriname buitengewoon goed aardt, maar die zich eveneens bijzonder goed leent voor een land waar men geheel met contract-arbeiders werkt. Men kan practisch bijna het geheele jaar oogsten. Deze koffie heeft echter ongebrand een onaangename lucht, welke van invloed is op den prijs, terwijl verder de markt beperkt is. Zoolang men die lucht niet verbetert en het niet gelukt een ruimere markt te vinden, zal voor uitbreiding dezer cultuur wel weinig animo zijn. Integenstelling met een jaar of zes geleden toen door lagere prijzen de toestand der koffieondernemingen in de kolonie weinig rooskleurig was, is deze thans goed en zijn de moeilijke jaren door velen alweer vergeten. Het doel moet zijn den kostprijs zoodanig te verlagen, dat de levensvatbaarheid van de cultuur wordt verhoogd. Nu hoopte Prof. Stahel door het uitplanten van enten van superieure moederboomen een gemiddelde productiestijging te kunnen verkrijgen en schreef ZEdl. (1922), ,dat een maximumproduct van 10 baal (van 100 KG.) per H.A. evenmin te hoog is".

We kunnen niet anders doen dan hopen dat de verwachte resultaten worden bevestigd. Men verwacht eveneens van hooger toppen der koffieboomen productievermeerdering. Lettende op de beweging, welke in het geheel Oosten heerscht en verder op de gevolgde bestuurspolitiek in de kolonie, die van de nakomelingen der immigranten menschen maakt, die weinig arbeid presteeren, dient men, naar ik reeds herhaaldelijk elders heb geschreven, te trachten de beste kleurlingen als deelbouwers aan de bedrijven te verbinden, waardoor een schakel kan worden gevormd tusschen ondernemer en vrije arbeiders. Met 
die deelbouwers zou dan voor de betaling een regeling moeten worden getroffen welke gebaseerd is op den koffieprijs met welken de kostprijs zou fluctueeren. Met dien prijs zouden dan de arbeidskosten fluctueeren.

\section{Citruscultuur.}

Vaststaat, dat sinaasappel-, mandarijn- en grapefruitboomen, om de voornaamste te noemen, in Suriname zeer goed gedijen, uitstekend produceeren en vruchten van zeer goede eigenschappen opleveren, dat verder in tegenstelling met verschillende andere citrusvruchten produceerende landen, w.o. Californië, geen belangrijke uitgaven noodig zijn voor grondbewerking, bemesting en ziektebestrijding, hetgeen niet wil zeggen, dat bij het inslaan dezer wegen de producties niet nog meer zullen stijgen.

Men dient niet te vergeten, dat de citruscultuur in Suriname tot op heden nooit goed is aangepakt geworden, waarmede hier bedoeld wordt, dat tot heden de noodige kundige leiding in dienst van naar perfectie der bedrijven strevende westersche ondernemers steeds heeft ontbroken. Het valt verder niet te ontkennen, dat het klimaat in de belangrijke citrusvruchtenproduceerende gebieden over het algemeen gematigder is dan dat van Suriname. In verband hiermede wensch ik op te merken, dat in tegenstelling met het laaglandvan Java de sinaasappel in het Surinaamsche laagland zoowel kwalitatief als kwantitatief een uitstekend product kan geven. Uit de verschillende mij verstrekte gegevens blijkt, dat ook de beoordeelingen uit het buitenland, w.o. Noord-Amerika en Canada eensluidend gunstig zijn. Ir. W. L. Utermark schrijft (Mededeeling No. 19. Afd. Hand. Museum. No. 4).: „Bijzonder gewaardeerd werden (Jaarbeurs Utrecht) vooral de graad en aard der zoetheid en de groote saprijkheid, welke laatste aanschouwelijk gedemonstreerd werd." Het is opmerkelijk, dat verschillende gewassen als bijv. suikerriet, koffie, cacao, mais, sinaasappel onder gelijke omstandigheden in het Surinaamsche laagland veel beter gedijen dan in dat van Java.

Een toestand het meest gelijkend op die van Suriname 
vinden we in Brazilië en speciaal in Bahia. Uit een Bulletin van het Dep. van Landbouw in Noord-Amerika neemt de Heer Utermark het een en ander over. Hij schrijft o.m.: „Bahia is het vaderland der navel-sinaasappelen. ....Het klimaat is warm en vochtig met natte en droge seizoenen.... Niet alleen in den regentijd valt er regen, ook in het droge seizoen. De kweekers van Bahia zeggen: des te heviger en vaker de regens vallen des te beter fruit krijgt men. De gem. jaarlijksche hoeveelheid regen is 1524 m.M. (Sur. ong. 2300 mM.). De temp. blijft gedurende het geheele jaar ongeveer constant en vertoont ook gedurende een etmaal geen groote verschillen; gemiddeld is ze 76,4 grd. F. (Sur. 1899-1927 80,2 grd. F.). De onmiddellijke omstreken van Bahia zijn heuvelachtig, eene hoogte vertoonende van $100-200$ voet. Bijna alle citrustuinen zijngelegen op de toppen der heuvels veelal langs de heuvelglooiingen afdalend tot aan de randen der vallei". Ook de verdere beschrijving der terreinen wijst op een groote overeenkomst met Suriname speciaal de streken in en vooral bezuiden de savannazône.

\section{Suiker.}

De meeste factoren, welke den kostprijs van suiker bepalen zijn in Suriname zeer gunstig, waardevoller dan op Java. Ongunstiger dan in dit laatste land is de factor der arbeidsvoorziening. In de eerste plaats is men in Suriname afhankelijk van den aanvoer van werkkrachten van buiten, in de tweede plaats zijn de arbeidskosten er hooger niettegenstaande de Regeering thans een deel dezer kosten voor haar rekening neemt. Het is vooral de eerstgenoemde, een geregelde aanvoer van werkkrachten dus, welke door verschillende onzer grootste ondernemers als een belangrijke nadeelige factor voor Suriname wordt beschouwd. We zien sedert 1918 in het naburige Demerara tot welke moeilijkheden zulks kan leiden. Er is echter nog een factor, welke voor alle Surinaamsche bedrijven nadeelig is en wel deze, dat een onverstandige bestuurspolitiek een weinig arbeidspresteerende bevolking kweekt waardoor de volgende geslachten der Aziatische immi- 
granten evenals de inheemsche bevolking als werkers van beteekenis voor de kolonie vrijwel verloren gaan.

In 1921, vóór belangrijke verbeteringen in de fabrieksinstallatiën werden aangebracht, stond het suikerbedrijf in de kolonie vergeleken met Java en andere landen op een laag peil, terwijl ook de rietcultuur en het transport veelal verre van volmaakt waren. De grootte der meeste ondernemingen, zoowel als de geheele bedrijfsorganisatie waren eveneens doorgaans onvoldoende. Ondanks het ingebreke blijven van het inslaan van die wegen, waarlangs o.m. de Javasuikerindustrie tot een lagen suikerkostprijs is gekomen, heeft de Surinaamsche suikerindustrie het tot heden kunnen bolwerken. De resultaten werden bereikt met belangrijk minder intensieve bodembewerking dan op Java. De door mij bedoelde weg is die van het kweeken van meerwaardige rietsoorten. Hieraan is noch door de fabrikanten noch door het proefstation iets van beteekenis gedaan. Het ware m.i. dan ook vrij wat verstandiger geweest indien de Regeering instede van de aanvoerkosten van Javaansche werkkrachten te dragen, een deskundige van erkende bekwaamheid naar Suriname had gezonden (eventueel daarvoor financieelen steun aan de planters had toegezegd) en hem de beschikking over de noodige middelen had gegeven om te trachten door het kweeken van meerwaardige rietsoorten de opbrengsten per eenheidsoppervlak te doen stijgen en langs dien weg de bestaanszekerheid der fabrieken te vergrooten. Een opleving van eenige beteekenis van de rietsuikerindustrie in de kolonie is slechts dan te verwachten, indien de suikerkostprijs op een belangrijk lager niveau kan worden gebracht en de bedrijfszekerheid toeneemt. In verband met dit laatste merk ik op, dat ik reeds gedurende verscheidene jaren achtereen gewezen heb op het groote belang, welke deze industrie heeft bij een loonende vervanging van een zeer groot deel van de thans noodige handenarbeid door mechanischen arbeid. Op deze belangrijke zaak zal ik hier niet verder ingaan, maar wil er nog slechts op wijzen, dat indien langs dien weg ooit iets van beteekenis zal worden bereikt, er dient te worden 
gebroken met het tegenwoordig systeem van indeeling der terreinen en voorts dat alleen kabeltractie voor een mechaniseering van den rietverbouw in hoofdzaak van nut kan zijn. Over deze nieuwe indeeling kan ik hier niet uitwijden, het zij echter voldoende te verklaren, dat zij door verschillende deskundigen is bestudeerd geworden en de conclusies optimistisch luiden. De practijk zal hier echter moeten beslissen. Hoewel gaarne wordt toegegeven, dat de rietopbrengsten op de zware polderklei belangrijk grooter zal zijn dan op lichteren grond, dient naar voren te worden gebracht, dat het suikergehalte van het riet op den laatsten grond gewonnen veel hooger is als gemakkelijk kan worden bewezen uit geschriften van vroegere planters. Integenstelling met dien ouden tijd beschikken wij thans over heel wat meer middelen om de opbrengsten per eenheidsoppervlak op loonende wijze belangrijk te vermeerderen. Het behoeft verder geen betoog als ik verklaar, dat een mechanisch, een intensief rietbedrijf naderende cultuur, op minder zwaren grond zeer goed en economisch uitvoerbaar is.

Dat de Surinaamsche klei zooveel meer arbeid vordert om een behoorlijke rietopbrengst te verzekeren dan zware kleigronden in andere streken, als Java en Cuba, is onjuist. De gunstige vrijwel over het geheele jaar verdeelden regenval maakt de Surinaamsche kleigronden veelal beter bewerkbaar dan die van Cuba en Java, waar sommige bewerkingen op het invallen der regens moeten wachten, tenzij voldoende arbeiders beschikbaar zijn die met breekijzers en dergelijke voorwerpen de harde massa moeten verbrokkelen.

Zoolang wij voor de ontwikkeling van Suriname als hoofdvoorwaarde den goedkoopen koelie stellen, komen we er nooit.

Naar mijn meening dient elk wetenschappelijk hulpmiddel dat te gebruiken is om te komen tot een lageren kostprijs van de producten te worden aangewend en zal het langs dien weg kunnen gelukken, dat de bedrijven een hoogeren loonstandaard, welke de bedrijfszekerheid doet toenemen, kunnen dragen. 
Bij een ernstige beschouwing van het vraagstuk der opleving van Suriname dienen we rekening te houden met de zich in het Oosten wijzigende toestanden, met de hoogere levenseischen van in de kolonie geboren Aziaten. Ondernemers moeten trachten zich zooveel mogelijk vrij te maken van handenarbeid en de beste hunner werklieden opvoeden tot deelbouwers in hunne bedrijven, waardoor een schakel wordt gevormd tusschen ondernemers en de vele vrije arbeiders in de kolonie. Een grondige wijziging der tot heden gevolgde bestuurspolitiek is zeker niet het minst noodig.

De bevolking.

Reeds meermalen heb ik over de bevolking van Suriname geschreven en heb ik o.m. in mijn bij Martinus Nijhoff verschenen brochure: „Een deel der taak van Nederland in Suriname" eenigszins uitvoerig stilgestaan bij de negroiden, zooals ik gemakshalve de vele negermengingen in de kolonie maar heb genoemd. Elk volk, dat te gemakkelijk aan den kost kan komen en door een regeering te tegemoetkomend wordt behandeld, vervalt tot een klagende, weinig arbeidpresteerende massa, lijdt op een bodem, welke met weinig arbeid flink produceert, gebrek.

De groote Amerikaansche en andere bedrijven in Centraal-Amerika, incl. Cuba, hebben voor een goed deel hun snelle opkomst en groote ontwikkeling te danken aan den negerarbeider uit dat deel van West-Indië waar de menschen bij niet werken ten ondergaan. Ik zal hieromtrent niet in finesses treden, het bewijs is echter gemakkelijk te leveren.

Wij beleven thans vooral ook in ons land een tijd waarin te veel van schoolopleiding wordt verwacht en niet scherp genoeg wordt ingezien, dat om een maatschappij vooruit te helpen men moet beginnen met arbeidzame menschen. Het was dan ook te verwachten, dat door oprichting van een landbouwschool of -cursus in Suriname getracht zou worden jongelieden tot landbouwers van hooger peil te vormen. Ik ben in de gelegenheid geweest die opleiding van nabij te beschouwen en kan niet anders 
zeggen dan, dat wat door verstandige menschen verwacht werd, is uitgekomen. Het succes was nihil.

Nood leert de menschen veel, ook op landbouwgebied. Prof. K. von Meyenburg uit Bazel schreef in „Die Technik in der Landwirtschaft" van Jan./Febr. '27 een artikel: „Grundlagen der Landwirtschaft”. Hierin komt o.m. het volgende voor.

„Historiker und Sociologen frugen sich dagegenbisher vergeblich, wieso China seit 4000 Jahren so ungezaehlte Millionen Koepfe ernaehre, die nie auf Eroberungen auszogen, und deren Boden fruchtbar blieb".

Hier toch werden geen scholen, vereenigingen, tijdschriften, laboratoria etc. aangetroffen. Het antwoord is o.m. te zoeken in den sterken prikkel, welke door den strijd om het bestaan wordt opgewekt, en die de menschen noodzaakt zich in te spannen. We zien ditzelfde in Korea en Japan, al is hier de toestand de laatste tientallen jaren gewijzigd.

Voor me heb ik een rapport, waaruit duidelijk blijkt hoe de Creolen op Lelydorp - een plaatsje langs den trein in Suriname - op landbouwgebied aldaar niets hebben bereikt. De grond rond Lelydorp is niet rijk, terwijl een zeer slecht doorlatende onderlaag de waarde van die streek nog doet verminderen. Lelydorp werd sedert voor cultures waardeloos genoemd. Nu zien we er Javanen gunstige resultaten bereiken met eenige gewassen, terwijl in Europeesche kringen belangstelling is opgewekt voor een ananascultuur. Met vrij groote zekerheid kan worden voorspeld, dat de kinderen dier Javanen dergelijke gunstige resultaten daar niet zullen bereiken, dat zij geleidelijk zullen afdalen naar het type waarvan onze kolonie zoo rijk is.

Het volk in Suriname is in zijn geheel genomen niet kwaad; ik zie het meer als slachtoffer van een te weinig verstandige leiding. Wat meer gezond verstand en durf in die leiding en de bevolking wordt, zij het dan dat zulks niet direct zal worden erkend, een weldaad bewezen.

's-Gravenhage, December 1928. 